\title{
Derecho Procesal Civil
}

Maite Aguirrezabal Grünstein

Profesora investigadora

Universidad de los Andes

GESTIÓN PREPARATORIA Y PRESCRIPCIÓN DE LA ACCIÓN EJECUTIVA

\section{INTRODUCCIÓN}

En el presente trabajo se analiza la sentencia pronunciada por la Segunda Sala de la Corte de Apelaciones de La Serena con fecha 27 de marzo de 2017, en la causa rol n..$^{\circ}$ 40-2017 (rol de ingreso a la Corte), referida a la consideración de la interrupción de la prescripción con ocasión de la preparación de la vía ejecutiva.

El fallo resulta de gran relevancia por cuanto la decisión considera que no existe una unidad procesal entre la gestión preparatoria y el juicio ejecutivo para efectos de considerar si la gestión interrumpe permanentemente la prescripción de la acción ejecutiva.

\section{HEChOS RELEVANTES QUE MOTIVAN EL FALLO}

En estos autos rol 1474-2014 seguidos ante el Tercer Juzgado de Letras de la ciudad de Coquimbo, compareció la Sociedad Comercializadora de Frutos del País Las Cabras Limitada y deduce demanda ejecutiva en contra de Álvaro López Galleguillos, la que funda en la cobranza de unos cheques que la demandada ha girado en favor de la sociedad demandante por la suma total de $\$ 45524000$ más reajustes e intereses, los que fueron oportunamente protestados y no pagados.

Por medio de la correspondiente gestión preparatoria, y con fecha 18 de julio de 2014 se notificaron legalmente los protestos de los cheques cuya cobranza se ejecuta, quedando con ello preparada la vía ejecutiva.

Presentada la demanda ejecutiva, esta fue notificada con fecha 19 de febrero de 2016, y el ejecutado opuso la excepción contenida en el numeral 17 del ar. 464 del $C P C$, esto es, "prescripción de la deuda o sólo de la acción ejecutiva", la que funda en que ha comenzado a correr un nuevo plazo de prescripción de un año que se contará desde que el título quede perfecto para poder accionar ejecutivamente. En la especie este nuevo plazo de prescripción empezó a correr el día 19 de enero de 2015, fecha en que se efectuó la certificación de 
encontrarse preparada la vía ejecutiva y habiéndose mantenido la prescripción interrumpida entre el 18 de julio de 2014 y el 19 de enero de 2015.

Por consiguiente, señala que el día 19 de enero de 2015 se reanudó un nuevo cómputo del plazo de prescripción de un año de la acción ejecutiva que emana de los cheques de autos. Este plazo corrió sin interrupción. Agrega que el ejecutado fue notificado de la demanda ejecutiva y requerido de pago el día 19 de febrero de 2016, habiendo transcurrido a su juicio el plazo de prescripción, lo que hace que la acción se encuentre prescrita.

Contestando el traslado conferido respecto de las excepciones opuestas, el ejecutante señala que es erróneo lo expuesto por el demandado, al sostener que el plazo de prescripción corre nuevamente a partir de la certificación de que el demandado no pagó ni opuso tacha de falsedad de su firma y que la ley prevé la notificación judicial oportuna del protesto del cheque, lo que constituye una forma de iniciar el juicio ejecutivo según se desprende, a su juicio, del art. 178 del COT, habiéndose notificado el protesto de los cheques dentro del plazo del año previsto en el art. 34 de la ley de cuentas corrientes bancarias y de cheques y que, por lo tanto, la prescripción de la acción ejecutiva se interrumpió con dicha gestión.

Alega también que el ejecutado habría solicitado facilidades de pago y prórrogas de plazo, lo que a su juicio interrumpe naturalmente la prescripción.

Por sentencia de 28 de junio de 2016 el tribunal acoge la excepción de prescripción fundada en el hecho de que la demanda ejecutiva fue notificada el 19 de febrero de 2016, encontrándose vencida la prescripción de un año contado desde que quedó preparada la vía ejecutiva.

Apelado este fallo por el ejecutante, la segunda sala de la Corte de Apelaciones de La Serena, con fecha 27 de marzo de 2017, confirmó la sentencia de primera instancia, pero revocándola en lo que respecta a la imposición de costas y condenando al recurrente a pagarlas.

En su contra, el perdidoso dedujo recurso de casación en el fondo, el que fue declarado inadmisible por la Corte Suprema.

\section{NATURALEZA DE LA GESTIÓN PREPARATORIA DE LA VÍA EJECUTIVA}

La gestión preparatoria de la vía ejecutiva corresponde a un procedimiento judicial que busca perfeccionar o completar un título ejecutivo ${ }^{2}$.

\footnotetext{
${ }^{1}$ Que dispone: "no obstante lo dispuesto en el artículo 176, serán de la competencia del juez que hubiere sido designado anteriormente, las demandas en juicios que se hayan iniciado por medidas prejudiciales, por medidas preparatorias de la vía ejecutiva o mediante la notificación previa ordenada por el artículo 758 del Código de Procedimiento Civil; todas las gestiones que se susciten con motivo de un juicio ya iniciado y aquellas a que dé lugar el cumplimiento de una sentencia, fuera del caso previsto en la parte final del artículo 114".

${ }^{2}$ La Corte de Apelaciones de Concepción, en fallo de fecha 12 diciembre 1966, RDJ, tomo LXIII, sec. $2^{\text {a }}$, Concepción, 1966, p. 169, sostiene que gestión preparatoria de la vía ejecutiva con-
} 
Existe discusión en torno a si por su naturaleza constituye una gestión de tipo contencioso o voluntario.

Para Mario Casarino

"son ciertos procedimientos judiciales previos, que puede iniciar el acreedor en contra del deudor, destinados a perfeccionar o completar el título con el cual pretende iniciar una ejecución posterior" ${ }^{3}$

y, por lo tanto, se trataría de un asunto contencioso.

En cambio, para Raúl Tavolari es un acto de jurisdicción voluntaria. La jurisprudencia se inclina a considerarla como una gestión contenciosa, ello como una forma de comenzar el juicio ejecutivo ${ }^{4}$, señalando:

"la finalidad de las gestiones preparatorias de la vía ejecutiva es constituir, formar o perfeccionar un título con idoneidad para el cumplimiento forzado de la obligación que de él deriva, una vez cumplidas las exigencias legales previas tendientes a constituirlo. De allí que su carácter de gestión denota propiamente una actividad o ritualidad que se identifica con los actos no contenciosos o voluntarios, cuyo objetivo se concreta en perseguir el acreditivo de un título o atributo, esto es, el llamamiento del deudor para que reconozca su firma o confiere una deuda, un título una condición de idoneidad, una situación creadora de derechos" 5 .

Considera Alejandro Romero:

"la relevancia práctica de este debate se aprecia en materias como la interrupción de la prescripción, la constitución del deudor en mora, la

siste en "aquella gestión judicial contenciosa tendiente a crear un título ejecutivo ya sea en forma directa constituyendo el título mismo, o complementando determinados antecedentes, o bien supliendo las imperfecciones de un título con existencia incompleta". Su objeto es crear un título ejecutivo, que permite la entrada a este procedimiento, y dicha finalidad se logra en alguna de estas formas: a) creándose el título por la gestión misma, como sucede con la confesión judicial, en que no existe antecedente previo que consigne la obligación que se trata de hacer efectiva; b) completando mediante actuaciones judiciales ciertos antecedentes que justifican la existencia de la obligación, como en el caso de las notificaciones no personales de los protestos de las letras de cambio, pagarés y cheques y c) complementando las imperfecciones de un título con determinada actuación judicial, como la gestión de avaluación.

${ }^{3}$ Casarino (2009), tomo v, p. 52.

${ }^{4}$ La Corte Suprema ha declarado, por ejemplo, que la gestión preparatoria de la vía ejecutiva activa la cláusula de aceleración, y desde ese minuto se computa el plazo de prescripción. Cfr. en este sentido, sentencias dictadas por la Corte Suprema con fecha 13 de julio de 2009 en la causa rol n. ${ }^{\circ}$ 1891-2008; con fecha 24 de marzo de 2009, en la causa rol n. ${ }^{\circ} 973-2008$; con fecha 22 de julio de 2008, rol n. ${ }^{\circ} 2678-2007$; con fecha 17 de marzo de 2009, rol n. ${ }^{\circ} 871-2009$. En sentido contrario resolución de 2 septiembre 1938, n. ${ }^{\circ}$ 14, p. 82. RDJ., tomo xxxvI, sec. $1^{\text {a }}$, Santiago, 1938, p. 224. Fallos citados por Romero (2015), p. 32.

${ }^{5}$ Sentencia pronunciada por la Corte de Apelaciones de Santiago, 25 de octubre de 2004, en los autos caratulados Monckeberg Bruner, Paulina con Village S.A, rol n. 1892-2001. 
competencia del tribunal, el efecto de cosa juzgada, la posibilidad de alegar el abandono del procedimiento, el régimen de recursos, etc." ${ }^{6}$,

agregando:

"el tema se debería zanjar considerando más que la naturaleza contenciosa o voluntaria, los efectos procesales de la litispendencia, que son los siguientes: a) nace la posibilidad de aplicar la sanción del abandono del procedimiento; b) nacen todos los derechos, obligaciones y cargas que impone la existencia de la relación procesal; c) se produce la 'perpetuatio legitimationis', en virtud de la cual quienes estaban legitimados al momento de la notificación de la demanda, en principio mantienen dicha calidad durante el transcurso del proceso; d) es posible desistirse de la acción"7.

Otro aspecto interesante en cuanto a su naturaleza es que, aunque al igual que las medidas prejudiciales, corresponden a gestiones previas al juicio principal, pero con importantes diferencias.

Primero, las medidas prejudiciales pueden ser gestionadas tanto por el futuro demandante como por el futuro demandado, mientras que las gestiones preparatorias de la vía ejecutiva solamente pueden iniciarse por el acreedor 234 en contra del deudor.

Segundo, y atendiendo a lo anterior, difieren también en su finalidad. Mientras las medidas prejudiciales pueden cumplir con una finalidad preparatoria, probatoria o precautoria, las gestiones preparatorias de la vía ejecutiva solo tienen por objetivo perfeccionar o completar el título ejecutivo.

Tercero, difieren en las consecuencias derivadas del fracaso de la gestión. En el caso de las primeras, tienen relación con el cumplimiento de ciertas cargas procesales para el citado y las consecuentes sanciones derivadas del incumplimiento de la carga impuesta, especialmente en materia probatoria.

En el caso de las segundas, si fracasa la gestión preparatoria no quedará preparada la vía ejecutiva, haciéndose imposible una posterior ejecución en los términos del art. 434 y siguientes del $C P C$ debiendo optar el solicitante por otras alternativas procesales.

\section{GESTIÓN PREPARATORIA E INTERRUPCIÓN DE LA PRESCRIPCIÓN}

El problema de fondo en la sentencia que se comenta tiene especial relación con si la gestión preparatoria de la vía ejecutiva se vincula con el procedimiento

\footnotetext{
${ }^{6}$ Romero (2015), p. 33.

${ }^{7}$ Ibid.
} 
ejecutivo posterior constituyendo una unidad procesal, y de ser así, si la notificación de la gestión preparatoria interrumpe definitivamente la prescripción de la acción ejecutiva.

La jurisprudencia mayoritariamente ha considerado que ambos procedimientos constituyen una unidad y que, por lo tanto, basta con que se notifique la gestión preparatoria para que se interrumpa la prescripción.

Los tribunales y la Corte Suprema en especial han determinado de manra reiterada que dicho propósito se cumple mediante todo recurso judicial interpuesto por el acreedor en resguardo del derecho que le pertenece y al cual la prescripción que corre en su contra amenaza con extinguir, y no solo la demanda que prevé y reglamenta el art. 254 del $C P C^{8}$, ya que la expresión recurso judicial debe entenderse en un sentido más amplio, como toda acción hecha valer ante la justicia y encaminada a obtener o resguardar un derecho amenazado ${ }^{9}$.

Agrega la Corte Suprema que incluso la expresión "demanda judicial" debe ser entendida en un sentido amplio, como todo acto realizado por el acreedor ante los tribunales, ya sea para cobrar su crédito o para efectuar las gestiones que lo sitúen en condiciones de hacerlo, y que lo que interesa para los efectos de la interrupción civil es que el acreedor salga de su inactividad y gestione ante los tribunales con la intención de obtener la satisfacción de su crédito, cumpliéndose con esta exigencia a través de la demanda o cualquier otra gestión que tienda directamente a posibilitarla ${ }^{10}$.

Se ha señalado en este sentido que la gestión preparatoria, por considerarse dentro del concepto de recurso judicial, posee

"la virtud de interrumpir el plazo de prescripción opuesta por el demandado, dado que con esas actuaciones el actor, salvó su pasividad y tomó el camino de exigir judicialmente el cumplimiento de la obligación a su deudor renuente" 11 .

${ }^{8}$ Corte Suprema, en resolución de fecha 21 de noviembre de 1988. $R D J$, tomo 85, segunda parte, sección primera, Santiago, 1988, p. 206.

${ }^{9}$ Corte Suprema, en sentencia de 28 de junio de $1955, R D J$, tomo 52, segunda parte, sección primera, Santiago, 1955, p. 193. En este mismo sentido en resolución de fecha 3 de julio de 2019, en los autos rol n. ${ }^{\circ} 731-2019 \mathrm{y} \mathrm{rol} \mathrm{n.}{ }^{\circ} 25.034-2018$ Santiago, en sentencia de diez de mayo de dos mil diecisiete. El mismo criterio se repite en sentencia de fecha 10 de mayo de 2017, dictada en los autos rol n. ${ }^{\circ} 10.376-2017$.

${ }^{10}$ Sentencia dictada en los autos rol no 1729/2015. La Corte de Apelaciones de San Miguel repite el criterio en sentencia de fecha 10 de febrero de 2016. Se señala en esta resolución: "se ha entendido, tanto por la doctrina como por la jurisprudencia que la expresión 'requerimiento' es equivalente a 'demanda' o 'acción judicial'”. Coincide Domínguez (2009), p. 240 con esto criterio, pero considera que existe una hipótesis en que no es posible ampliar la noción de demanda. Se trata de la situación prevista en el artículo 100 de la Ley n. ${ }^{\circ}$ 18092, que exige demanda judicial de cobro de letra de cambio o pagaré.

${ }^{11}$ Criterio establecido por la Corte Suprema en la causa rol n. ${ }^{\circ} 4232 / 2009$ en sentencia de 19 de julio de 2010 . 
A lo anterior deben agregarse diversas disposiciones que contempla la interrupción de la prescripción a partir del requerimiento, tales como el art. 2523 del Código Civil ${ }^{12}$.

Por lo anterior, nuestra jurisprudencia ha concluido:

"la interrupción de la prescripción es un tema inherente a dicha institución jurídica, pues el legislador se ha preocupado de resguardar el derecho de los acreedores, aún cuando no hayan ejercido con prontitud su derecho a exigir el cumplimiento de la obligación que debe satisfacer su deudor, otorgándole la facultad de interrumpir el plazo necesario mientras no se haya completado, haciéndole perder al deudor todo el tiempo transcurrido" ${ }^{13}$,

y que:

"si el legislador de la Ley $\mathrm{n}^{\circ} 19.983$ hubiere querido suprimir la interrupción de la prescripción en la materia, lo habría expresado claramente, invocando las razones que lo hubieren motivado para tal fin" ${ }^{14}$.

En lo que respecta específicamente a la gestión preparatoria de notificación judicial de los protestos de cheques, debe recordarse que el art. 100 de la Ley 236 n. ${ }^{\circ}$ 18092, aplicable en la especie por expresa disposición del art. 11 de la Ley sobre Cuentas Corrientes Bancarias y Cheques, no señala normas acerca de la interrupción del plazo de la prescripción, disponiendo:

"la prescripción se interrumpe sólo respecto del obligado a quién se notifique la demanda judicial de cobro de la letra, o la gestión judicial necesaria o conducente para deducir dicha demanda o preparar la ejecución”.

Por lo tanto, nuestra jurisprudencia arriba a la conclusión de que el plazo de prescripción que prevé el art. 34 de la Ley de Cuentas Corrientes y Cheques, y que debe computarse a partir de la fecha del protesto del documento mercantil invocado, se ha interrumpido con la respectiva notificación efectuada al girador, es decir, con la notificación de la gestión preparatoria de la ejecución ${ }^{15}$.

${ }^{12}$ Que dispone que las acciones que prescriben en corto tiempo se interrumpen desde que interviene pagaré u obligación escrita o concesión de plazo por el acreedor o, bien, desde que interviene requerimiento.

${ }^{13}$ Sentencia pronunciada por la Corte Suprema en la causa rol n. ${ }^{\circ} 4232 / 2009$, de 19 de julio de 2010 .

${ }^{14}$ Sentencia pronunciada por la Corte Suprema en la causa rol n. ${ }^{\circ} 4232 / 2009$, de 19 de julio de 2010 .

${ }^{15}$ Sentencia pronunciada por la Corte Suprema en la causa rol n. ${ }^{\circ} 5911 / 2010$. En el mismo sentido, sentencias de 1 de septiembre de 2010, de 14 de octubre de 2011; 3 de noviembre de 2015, en la causa rol n. ${ }^{\circ} 6891 / 2015$ y en sentencia de 9 de noviembre de 2015. 
La normativa citada debe también relacionarse con el ya referido art. 178 del COT, en cuanto prevé que las demandas en juicios que se hayan iniciado por medidas prejudiciales o por medidas preparatorias de la vía ejecutiva serán de competencia del juez que haya conocido de esa gestión previa.

Concluye nuestro máximo tribunal:

"del examen de las disposiciones normativas transcritas se desprende que la gestión preparatoria de notificación de protesto de cheque y el juicio posterior, en este caso ejecutivo, constituyen una unidad procesal, aún cuando materialmente existan dos expedientes diversos, puesto que se formará el proceso con los escritos, documentos y actuaciones de toda especie que se presenten o verifiquen en el juicio, según indica el artículo 29 del Código de Procedimiento Civil, a lo cual se agrega que el legislador sólo ha requerido en forma perentoria que la primera notificación a las partes o personas a quienes haya de afectar sus resultados, deberá hacérselas personalmente, atendido lo ordenado por el artículo 40 del mismo Código, la que se entiende cumplida al notificarse la gestión preparatoria de la vía ejecutiva por lo que, luego, la resolución que provee la demanda, ordenando el despáchese, puede notificarse por cédula, en atención al hecho que el sistema adoptado en el Proyecto -según se manifiesta en el Mensaje del Código de Procedimiento- consiste en practicar una primera notificación personal al demandado, rodeándola de todas las seguridades necesarias para su regularidad, e imponer en seguida a las partes la obligación de mantener vigilancia activa sobre la marcha del proceso autorizando para ello las notificaciones por cédula y aún por la simple inscripción en los estados de las secretarías”.

De modo minoritario nuestra jurisprudencia ha señalado, siguiendo los lineamientos del fallo que se analiza, que el efecto extensivo de la interrupción se prolonga durante la tramitación de la gestión, reanudándose a partir de entonces un nuevo computo del término especial de prescripción, de manera que si entre esa fecha y la oportunidad en que se llevó a cabo la notificación de la demanda ejecutiva ha transcurrido más de un año, la acción se encontraría prescrita ${ }^{16}$.

La Corte, de esta manera, plantea un problema en cuanto a la determinación de la época en que deberá reanudarse el nuevo cómputo del plazo, toda vez que, una vez producida la interrupción se inicia un nuevo término de prescripción, generalmente, de la misma naturaleza que el precedente.

De esta forma, ha señalado:

"el acto interruptivo provoca, indudablemente, la pérdida del tiempo de prescripción ya transcurrido, sin perjuicio de que el plazo pueda

${ }^{16}$ Sentencia pronunciada por la Corte Suprema en la causa rol n. ${ }^{\circ} 9201 / 2011$ de 20 de octubre de 2011. Reitera el criterio en sentencia de 27 de marzo de 2012. 
comenzar a correr nuevamente y, tratándose de una interrupción civil por demanda judicial o por cualquier otro recurso de tal carácter, es menester concluir que el efecto interruptivo deberá entenderse prolongado con cada acto procesal que renueve el ejercicio de la actividad jurisdiccional" 17 .

Así lo ha señalado también la doctrina, pero colocando de relieve las dificultades procesales que acarrea esta "puesta a cero del contador", en lo que tiene relación con la pérdida de efectos del plazo transcurrido con anterioridad a la interrupción ${ }^{18}$.

Para llegar a la anterior conclusión, ha señalado la Corte que si se examinan conjuntamente los arts. 100 de la Ley n. ${ }^{\circ} 18092$ y 178 del COT,

"se desprenden dos consecuencias jurídicas, la primera, que la notificación de la gestión preparatoria interrumpió la prescripción que comenzó a correr con el protesto de los instrumentos fundantes de la ejecución y, la segunda, que terminado el efecto interruptivo del acto aludido, una vez que culminó la etapa previa, el término establecido por el legislador para que opere la antedicha institución, comenzó a correr nuevamente".

Niega, por lo tanto, el carácter unificado del procedimiento ejecutivo, ya que:

"aun cuando constituyen una secuencia procesal, dependiendo el inicio del segundo del resultado del primero, ello no significa que se identifiquen como un solo juicio",

puesto que el hecho de que el procedimiento ejecutivo deba tramitarse ante el mismo tribunal que conoció de la gestión preparatoria, obedece a que hay regla especial de competencia que, de no existir, obligaría a recurrir a la regla general.

Para esta posición, entonces, es claro que el juicio ejecutivo es un nuevo procedimiento y no una mera continuación procesal de la instancia preparatoria ${ }^{19}$.

Sobre la base del antedicho presupuesto fáctico, los jueces concluyen que, aun cuando la gestión preparatoria y el juicio posterior constituyan una unidad procesal, lo cierto es que producida la interrupción de la prescripción por la notificación del protesto en la gestión preparatoria, este cómputo vuelve a

\footnotetext{
de 2014.

${ }^{17}$ Sentencia pronunciada por la Corte Suprema en la causa rol n. ${ }^{\circ} 323 / 2014$, de 10 de junio

${ }^{18}$ Cfr. en este sentido, García (2011), p. 183 y ss.

${ }^{19}$ Sentencia pronunciada por la Corte Suprema en la causa rol n. ${ }^{\circ} 6203 / 2013$, de 31 de julio de 2014.
} 
reiniciarse hasta que opere nuevamente por vía legal su cese, de modo que el plazo de prescripción ha de computarse desde que fuera primitivamente interrumpido con la notificación de la gestión preparatoria. En consecuencia, al constatar que ha transcurrido más de un año entre la fecha de notificación de la gestión preparatoria y la notificación de la demanda ejecutiva, procede que se declare la prescripción ${ }^{20}$.

\section{Conclusiones}

1) La doctrina mayoritaria en la jurisprudencia sostiene la tesis de que la prescripción de la acción ejecutiva se interrumpe con la notificación de la gestión preparatoria y una vez terminada esta gestión, el plazo de prescripción se mantiene interrumpido.

2) Sin perjuicio de lo anterior, existe también una tesis jurisprudencial minoritaria, como la del caso que se analiza, en que nuestra Corte Suprema ha considerado que el plazo de prescripción vuelve a comenzar, sin perjuicio de la interrupción que haya sufrido con ocasión de la gestión preparatoria.

3) El supuesto anterior supone que, si entre la certificación de que la vía ejecutiva se encuentra preparada y la notificación de la demanda transcurre más de un año, para el caso de las acciones de corto tiempo, el demandado se encuentra legitimado para alegar la excepción de prescripción con resultados favorables.

${ }^{20}$ Sentencia pronunciada por la Corte Suprema en la causa rol n. ${ }^{\circ} 30897 / 2014$, de 30 de marzo de 2015. En el mismo sentido, en los autos rol n. ${ }^{\circ}$ 14879/2016, de 1 de agosto de 2016; rol n. ${ }^{\circ}$ 7743/2016 de 31 de agosto de 2016. Esta última sentencia acordada contra el voto del ministro Jaime Balmaceda, quien fue de opinión de revocar el referido fallo y en su lugar acoger la excepción de prescripción opuesta, absolviendo a la ejecutada, teniendo para ello en consideración: " $1^{\circ}$.- Que en el actual estado de la doctrina y la jurisprudencia sobre la materia no existe mayor controversia en orden a que la notificación de la gestión preparatoria es una de las formas que puede revestir la 'demanda judicial' a que se refiere el inciso final del artículo 2518 del Código Civil, de modo tal que produce el efecto de interrumpir civilmente la prescripción. Ahora bien, la interrupción de la prescripción genera como consecuencia la pérdida del tiempo transcurrido, pero ese resultado deja de producirse si se configura alguno de los casos del artículo 2503, conforme lo prevé la misma regla antes citada, y de acuerdo a este último precepto ello tiene lugar en tres situaciones: si la notificación de demanda no ha sido hecha en forma legal, si el acreedor se desistió expresamente de la demanda o se declaró abandonado el procedimiento o si el demandado obtuvo sentencia de absolución. De este modo, notificada legalmente la gestión preparatoria o la demanda que da inicio al juicio propiamente dicho, las únicas razones que de acuerdo a la ley tienen la aptitud suficiente para hacer que cesen los efectos interruptivos que ella misma ha previsto, son cualquiera de los tres indicados en el precepto y no otros, de manera que en tanto no se declare la nulidad de la notificación de la actuación a la que se atribuía virtud de interrumpir, se tenga presente el desistimiento del actor, se declare el abandono del procedimiento o se dicte sentencia definitiva que desestime la demanda, el término de la prescripción debe entenderse permanece interrumpido, lo que impide que opere la prescripción como modo de extinguir las obligaciones". 
4) Creemos que sin perjuicio de la posición que se adopte, es razonable considerar para estos efectos la obligación de colaboración que las partes poseen con la administración de justicia, y que ello supone agilizar la tramitación de los procesos evitando su paralización por largo tiempo.

\section{Bibliografía CITADA}

Casarino Viterbo, Mario (2009). Manual de Derecho Procesal. Santiago: Editorial Jurídica de Chile. Tomo v.

Domínguez Águila, Ramón (2009). La prescripción extintiva. Doctrina y Jurisprudencia. Santiago: Editorial Jurídica de Chile.

García NovoA, César (2011). Iniciación, interrupción y cómputo del plazo de los tributos. Madrid: Marcial Pons.

Romero Seguel, Alejandro (2015). El proceso de ejecución. Santiago: Universidad de los Andes. 